\title{
ESTRUTURA DAS DEMONSTRAÇÕES CONTÁBEIS: UM ESTUDO DO NÍVEL DE CONHECIMENTO DE ESTUDANTES DE ADMINISTRAÇÃO
}

STRUCTURE OF FINANCIAL STATEMENTS: A STUDY OF THE LEVEL OF KNOWLEDGE OF MANAGEMENT STUDENTS

NADIELLI MARIA DOS SANTOS GALVÃO

Universidade Federal de Sergipe

ANDREZA CRISTIANE SILVA DE LIMA

Faculdade de Ciências Humanas de Pernambuco

LUANA LEITE PEREIRA DOS SANTOS

SENAI/PE

Recebido em 22/11/18

Avaliado pelo sistema double blind review

Aceito para publicação pelo Editor Chefe Dr. Leonardo José Seixas Pinto em 18/12/18 e publicado em 28/12/18

\section{RESUMO}

Este estudo tem como objetivo identificar o nível de conhecimento dos estudantes de administração quanto à finalidade das Demonstrações Contábeis obrigatórias no Brasil verificando se há associação entre o perfil do discente e seu nível de conhecimento. Para tanto, realizou-se uma pesquisa descritiva e quantitativa, sendo o instrumento de coleta um questionário contendo perguntas acerca do conjunto dessas demonstrações, o qual foi disponibilizado via online. Os dados foram tabulados no Excel $^{\oplus}$ e a análise de estatística descritiva e teste qui-quadrado foram realizadas no software Gretl. Os principais achados mostraram que as demonstrações contábeis mais conhecidas foram o Balanço Patrimonial, Demonstração do Resultado do Exercício e Demonstração dos Fluxos de Caixa. Sobre o conhecimento a respeito do conjunto desses documentos, o maior número de acertos correspondeu ao conteúdo do Balanço Patrimonial e o de menor acerto, a Demonstração do Valor Adicionado. O conhecimento que os estudantes se auto atribuíam coincidiu com maioria das respostas obtidas quanto a DFC, DVA, DRA e Notas Explicativas. Além disso, o nível de conhecimento quanto a esses demonstrativos, mostrou-se associado ao turno em que o aluno estuda, sendo o melhor desempenho apresentado por aqueles que estudam pela manhã, em seguida dos que cursam EaD. Por fim, ter cursado ou não a disciplina de contabilidade geral ou correlata, afetou o nível de conhecimento sobre o Balanço Patrimonial, DMPL, DRE e DLPA. Esses resultados podem contribuir para nortear professores de contabilidade que ministram tal conteúdo no curso de administração.

Palavras-chave: Administração; Conhecimento; Demonstrações contábeis.

\section{ABSTRACT}

This study aims to identify the level of knowledge of management students regarding the purpose of mandatory accounting statements in Brazil to verify if there is an association between the profile of the student and his level of knowledge. For this, a descriptive and quantitative research, the collection instrument being a questionnaire containing questions about the set of these statements, which was made available online. The data were tabulated in Excel ${ }^{\circledR}$ and the analysis of descriptive statistics and chi-square test were performed in Gretl software. The main findings showed that the most well-known financial statements were the Balance Sheet, Statement of Income for the Year and Statement of Cash Flows. Regarding the knowledge about the set of these documents, the greatest number of hits corresponded to the contents of the Balance Sheet and the smaller hit, the Statement of Added Value. The knowledge that the 
students attributed themselves coincided with most of the answers obtained regarding CFD, DVA, DRA and Explanatory Notes. In addition, the level of knowledge about these statements was shown to be associated with the student's turn, with the best performance presented by those who study in the morning, followed by those who study EaD. Lastly, whether or not the general or related accounting discipline has affected the level of knowledge about the Balance Sheet, DMPL, DRE and DLPA. These results may help guide accounting teachers who deliver such content in the course of administration.

Keywords: Accounting statements; Administration; Knowledge.

\section{INTRODUÇÃ̃O}

O termo 'conhecer' tem origem no grego gnosku, e significa possuir informação a respeito de algo, ter conhecimento, podendo denotar também o ato de chegar ao entendimento de certo assunto como resultado de habilidades aprendidas ou passadas por alguma experiência (LAW; NIDA, 2013). Ao administrador é exigido múltiplos conhecimentos. Por isso, nos cursos de bacharelado em administração são apresentadas aos discentes diversas disciplinas, das mais diversas áreas, inclusive contabilidade.

Dessa forma, a apresentação da contabilidade no curso de administração tem como objetivo prover ao futuro profissional, habilidades mínimas para que este se utilize das informações contábeis destinadas às tomadas de decisões. Nesse sentido diversos estudos tais como Costa et al. (2010), Ismail e Kasin (2011), Borges e Mafra (2013), Muda et al. (2013), Panhoca et al. (2014), Xavier Filho et al. (2015), Floret (2017), Lois, Tabouratzi e Makrygiannakis (2017) procuraram verificar a relação dos estudantes de administração com a disciplina de ciências contábeis. No entanto, nenhum dos estudos citados abordou o nível de conhecimento dos alunos de administração sobre temas contábeis de forma específica.

Sabe-se, porém, que é imprescindível que o administrador conheça a contabilidade e saiba utilizá-la no processo decisório (DIAS FILHO, 2000). Isto ainda se torna mais claro na hora em que o administrador precisar analisar as demonstrações contábeis da organização para assim compreender a saúde econômica e financeira da sua empresa, visando tomar medidas para melhorar tal desempenho (SANTOS; 2012).

No que se refere aos demonstrativos contábeis, de acordo com o Pronunciamento Contábil 26 (R1) - Apresentação das Demonstrações Contábeis, são peças obrigatórias de divulgação: Balanço Patrimonial, Demonstração do Resultado, Demonstração do Resultado Abrangente (se houver resultados abrangentes no período), Demonstração dos Fluxos de Caixa, Demonstração das Mutações do Patrimônio Líquido e Demonstração do Valor Adicionado (obrigatória para empresas de capital aberto nos ternos da Lei 6.404 de 1976 e suas atualizações), além das notas explicativas.

Assim, o administrador precisa conhecer esses demonstrativos, tendo em vista serem os elementos que apresentam informações sobre a situação da sua organização, permitindo que este profissional tome decisões econômicas e financeiras mais adequadas para a realidade da empresa naquele momento. Mas, para isso, tal conhecimento deve ser repassado durante a graduação, fator que implica no seguinte questionamento: Qual o nível de conhecimento dos estudantes de administração quanto à finalidade das Demonstrações Contábeis obrigatórias no Brasil? Consequentemente, tem-se como objetivo identificar o nível de conhecimento dos estudantes de administração quanto à finalidade das Demonstrações Contábeis obrigatórias no Brasil, verificando se há associação entre o perfil desse respondente e seu nível de conhecimento, cujo perfil contemplou o turno em que estuda, tipo de instituição, e, ter cursado ou não disciplinas de contabilidade geral ou correlata.

Este estudo se justifica por procurar apontar o nível de entendimento de um dos principais grupos de usuários da demonstração contábil acerca do principal produto oferecido por esta ciência. Pode ajudar professores que lecionam disciplinas de contabilidade em cursos de 
administração a melhorarem o direcionamento do conteúdo passado aos estudantes. Servirá também de apoio aos conselhos de contabilidade, para que estes procurem meios de instruírem melhor os usuários da informação contábil, investindo, inclusive, em cursos de capacitação e atualização para este público.

Esta pesquisa está dividida em cinco seções, sendo esta uma seção introdutória, na qual foi contextualizado o tema, apresentado o objetivo da pesquisa, questão-problema e justificativa para realização do trabalho. A seguir é apresentada a revisão de literatura realizada com o intuito de conhecer os aspectos teóricos que deram subsídios às discussões de resultados. A terceira seção destaca a metodologia adotada para o alcance do objetivo proposto, que possibilitou o alcance de seus resultados, os quais são explanados na quarta seção do estudo. A quinta e última seção apresenta a conclusão do estudo, suas limitações e sumariza suas principais contribuições, também sugerindo temas para futuras investigações.

\section{REVISÃO DE LITERATURA}

\subsection{Demonstrativos Contábeis Obrigatórios no Brasil}

As demonstrações contábeis são relatórios emitidos após as entidades realizarem os registros dos fatos ocorridos nos elementos patrimoniais em determinado período, cujo objetivo é fornecer informações úteis aos seus usuários de forma que possam contribuir significativamente no processo de tomada de decisão. Esses documentos apresentam várias finalidades, as quais vão depender do tipo de usuário que esteja demandando a informação, tendo em vista que governos, órgãos reguladores e autoridades fiscais podem especificar o tipo de informação que necessitam (BRASIL, 2016).

Quanto aos documentos legais que ditam quais as peças contábeis devem ser elaboradas pelos preparadores, cita-se, inicialmente, a Lei 6.404/1976, mais conhecida como Lei das S/A, a qual pontua que no final de cada exercício social, toda entidade deve exprimir claramente a situação patrimonial e suas respectivas modificações por meio dos seguintes elementos: Balanço Patrimonial (BP), Demonstração dos Lucros ou Prejuízos Acumulados (DLPA), Demonstração do Resultado do Exercício (DRE), Demonstração dos Fluxos de Caixa (DFC), e, no caso de companhias abertas, a Demonstração do Valor Adicionado (DVA). Adicionalmente, a Lei estabelece que devem ser elaboradas também as Notas Explicativas, como complemento dos dados trazidos nas demonstrações anteriores (BRASIL, 1976).

Outro documento legal que trata das peças contábeis, refere-se à NBC TG 26 Apresentação das Demonstrações Contábeis, a qual adiciona ao conjunto desses documentos, a Demonstração do Resultado Abrangente (DRA) e a Demonstração das Mutações do Patrimônio Líquido (DMPL). Destaca-se que a DLPA, por se tratar de uma demonstração que apresenta as modificações ocorridas no resultado final da entidade (lucro ou prejuízo), pode ser elaborada dentro da DMPL, a qual contempla todas as contas do patrimônio líquido, inclusive, a de lucros/prejuízos. Diante desse apanhamento, lança-se a Figura 1, na qual os objetivos dessas demonstrações contábeis são explorados. 
Figura 1: Demonstrações contábeis exigidas no Brasil

\begin{tabular}{|c|c|}
\hline Balanço Patrimonial & $\begin{array}{l}\text { - Tem o objetivo de mostrar a posição financeira e patrimonial } \\
\text { da entidade, em determinada data, caracterizando tal } \\
\text { informação como estática. }\end{array}$ \\
\hline $\begin{array}{l}\text { Demonstração do Resultado do } \\
\text { Exercício }\end{array}$ & $\begin{array}{l}\text { - Tem o objetivo de apresentar os custos, receitas e despesas, } \\
\text { que incorreram para a entidade em determinado período, em } \\
\text { prol de fazer o levantamento do lucro ou prejuízo do período. }\end{array}$ \\
\hline $\begin{array}{l}\text { Demonstração do Resultado } \\
\text { Abrangente }\end{array}$ & $\begin{array}{l}\text { - Tem o objetivo de contemplar outras variações do patrimônio } \\
\text { líquido que vão impactar futuramente no resultado do } \\
\text { exercício, incluindo os respectivos ganhos ou perdas. }\end{array}$ \\
\hline Demonstração do Fluxo de Caixa & $\begin{array}{l}\text { - Tem o objetivo de retratar como aconteceram as } \\
\text { movimentações das disponibilidades (entradas e saídas de } \\
\text { caixa e equivalentes) durante um dado período. }\end{array}$ \\
\hline Demonstração do Valor Adicionado & $\begin{array}{l}\text { - Tem o objetivo de informar o valor da riqueza que foi gerada } \\
\text { pela entidade em determinado período, e como esse recurso } \\
\text { foi distribuído socialmente (funcionários, acionistas, credores } \\
\text { e governos). }\end{array}$ \\
\hline $\begin{array}{l}\text { Demonstração das Mutações do } \\
\text { Patrimônio Líquido }\end{array}$ & $\begin{array}{l}\text { - Tem o objetivo de evidenciar as mudanças que ocorreram no } \\
\text { patrimônio líquido (capital próprio) da entidade, ou seja, } \\
\text { entradas e saídas de recursos que são injetados na entidade } \\
\text { para ocorrer seu funcionamento. }\end{array}$ \\
\hline $\begin{array}{c}\text { Demonstração dos Lucros ou Prejuízo } \\
\text { Acumulados }\end{array}$ & $\begin{array}{l}\text { - Tem o objetivo de retratar como os lucros da entidade foram } \\
\text { distribuídos, ou, em caso de prejuízo, mostrar como houve a } \\
\text { compensação entre as reservas. }\end{array}$ \\
\hline Notas Explicativas & $\begin{array}{l}\text { - Tem o objeto de trazer informações adicionais a respeito do } \\
\text { alcance dos dados apresentados nas demais demostrações } \\
\text { contábeis, o que inclui a base de preparação, práticas } \\
\text { contábeis e demais informações relevantes. }\end{array}$ \\
\hline
\end{tabular}

Fonte: Elaborado pelas autoras (2018) a partir de Iudícibus et al. (2010).

Analisando a Figura 1, observa-se que cada demonstração contábil tem uma finalidade específica, portanto, apresenta informações diferenciadas quanto à situação econômicofinanceira da entidade, portanto, uma complementa a outra, sendo essas informações necessárias para o processo de tomada de decisão (IUDÍCIBUS et al., 2010). Diante desse exposto, Marion (2012), classifica o Balanço Patrimonial como uma das principais peças contábeis, pois nele é possível enxergar as demais demonstrações, tal como apontado na Figura 2 . 
Figura 2: Informações do Balanço Patrimonial oriundas de outras demonstrações

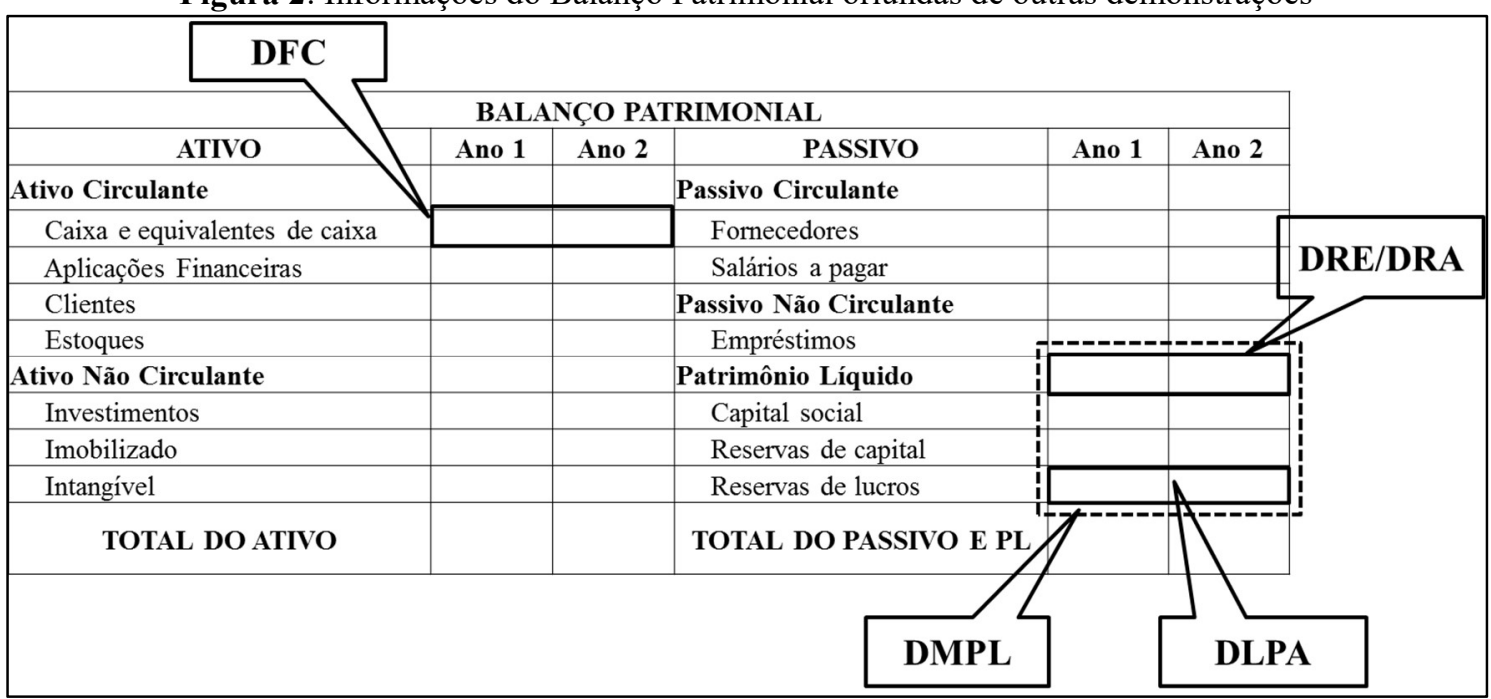

Fonte: Adaptado de Marion (2012).

A Figura 2 indica que no Balanço Patrimonial é possível enxergar o saldo da DFC, peça contábil responsável por mostrar os fluxos de entradas e saídas de dinheiro para a entidade em um período específico. O saldo da DLPA é retratado na conta Reservas de Lucros, dentro do Patrimônio Líquido, sendo o saldo desse último, detalhado na DMPL. Portanto, a DRE, DRA, DLPA e DMPL são demonstrações que apresentam as modificações que ocorreram nas contas do capital próprio da entidade. Ressalta-se que a DVA mostra como houve a distribuição da riqueza obtida pela entidade, cujos dados são semelhantes aos apresentados na DRE, por isso, constata-se que a DVA também apresenta informações retratadas no Balanço Patrimonial, pelo fato de estar atrelada à DRE.

Diante desse apanhamento, nota-se que o conhecimento desses demonstrativos deve ser propagado entre administradores tendo em vista que tais profissionais são os responsáveis por tomar as decisões que melhor tragam resultados positivos às entidades. Para tanto, é preciso compreender como anda a situação econômico-financeira da entidade, algo que se torna viável por meio do conjunto de demonstrações contábeis.

\subsection{O Ensino da Contabilidade no Curso de Administração}

A administração e a contabilidade são áreas que precisam estar atreladas no ambiente organizacional, tanto pela natureza interdisciplinar da primeira, tanto pela riqueza de informações fornecidas pela segunda, as quais são capazes de apoiar os gestores no processo de tomada de decisão (BORGES; NAVES, 2014).

Com o avanço dos estudos na ciência contábil, esta passou a ser considerada a própria linguagem dos negócios, passando a ser padronizada para qualquer organização e país, sendo amplamente divulgada e utilizada (ALMEIDA, 2016). Assim sendo, tanto importante é para o contador entender a finalidade de sua produção, quanto para o administrador saber interpretar as diversas informações geradas pela contabilidade, sendo que para isso, é necessário que a informação fornecida pela contabilidade seja suficientemente clara para que seus usuários compreendam (IUDÍCIBUS; MARTINS; CARVALHO, 2005).

Nesse sentido, tem-se como principal meio de divulgação de informações os demonstrativos contábeis, sendo que os administradores de uma organização se caracterizam como os principais usuários internos de tais documentos. Por isso, Alves (2007) infere que a contabilidade é uma disciplina necessária no curso de administração, pois assim, os estudantes 
futuros tomadores de decisões nas empresas, aprenderão a utilizar as informações geradas pela Contabilidade como ferramenta fulcral.

Para uma boa tomada de decisão é necessário, então, analisar de forma eficiente o demonstrativo contábil. Iudícibus (1998, p.20) define a análise de demonstrações contábeis como a arte de saber extrair relações úteis, para o objetivo econômico que tivermos em mente, dos relatórios contábeis tradicionais e de suas extensões e detalhamentos, se for o caso. Logo, para uma gestão eficaz é preciso que o gestor esteja familiarizado e saiba entender as informações geradas pelo Balanço Patrimonial, Demonstração de Resultado, Fluxo de Caixa, e demais demonstrativos.

Para Gitman (2010), uma das principais diferenças entre finanças e contabilidade está relacionada à tomada de decisões. Os contadores dedicam-se à coleta e apresentação de dados, já os administradores, então tomam as decisões.

No entanto, quando se observa os currículos dos cursos de administração das universidades e faculdades brasileiras, sempre se encontra(m) disciplina(s) voltada(s) para o ensino da contabilidade em alguma esfera. Porém, de pouca utilidade é o administrador, ou aspirante a tal, ter acesso a demonstrações contábeis e não saber interpretá-las. Borges e Mafra (2013) já apontavam que o ensino de contabilidade no curso de administração tem sido focado muito mais em 'como fazer' o demonstrativo e não 'como analisar', sendo que o papel do administrador será de intepretação e não de elaboração.

Dessa forma, o exercício de interpretar informações contábeis deve ser realizado desde a graduação para que cada estudante, sabendo da importância e demandas de seu próprio curso, não saia da academia e se surpreenda ao se deparar com uma realidade tão diferente do que lhe foi ensinado.

\subsection{Estudos Anteriores}

Nesta subseção são sumarizados estudos realizados anteriormente e que discutem o ensino de contabilidade em cursos de administração. O Quadro 1 esquematiza tais obras, evidenciando seus autores, objetivos e principais resultados.

Quadro 1: Resumo dos estudos anteriores.

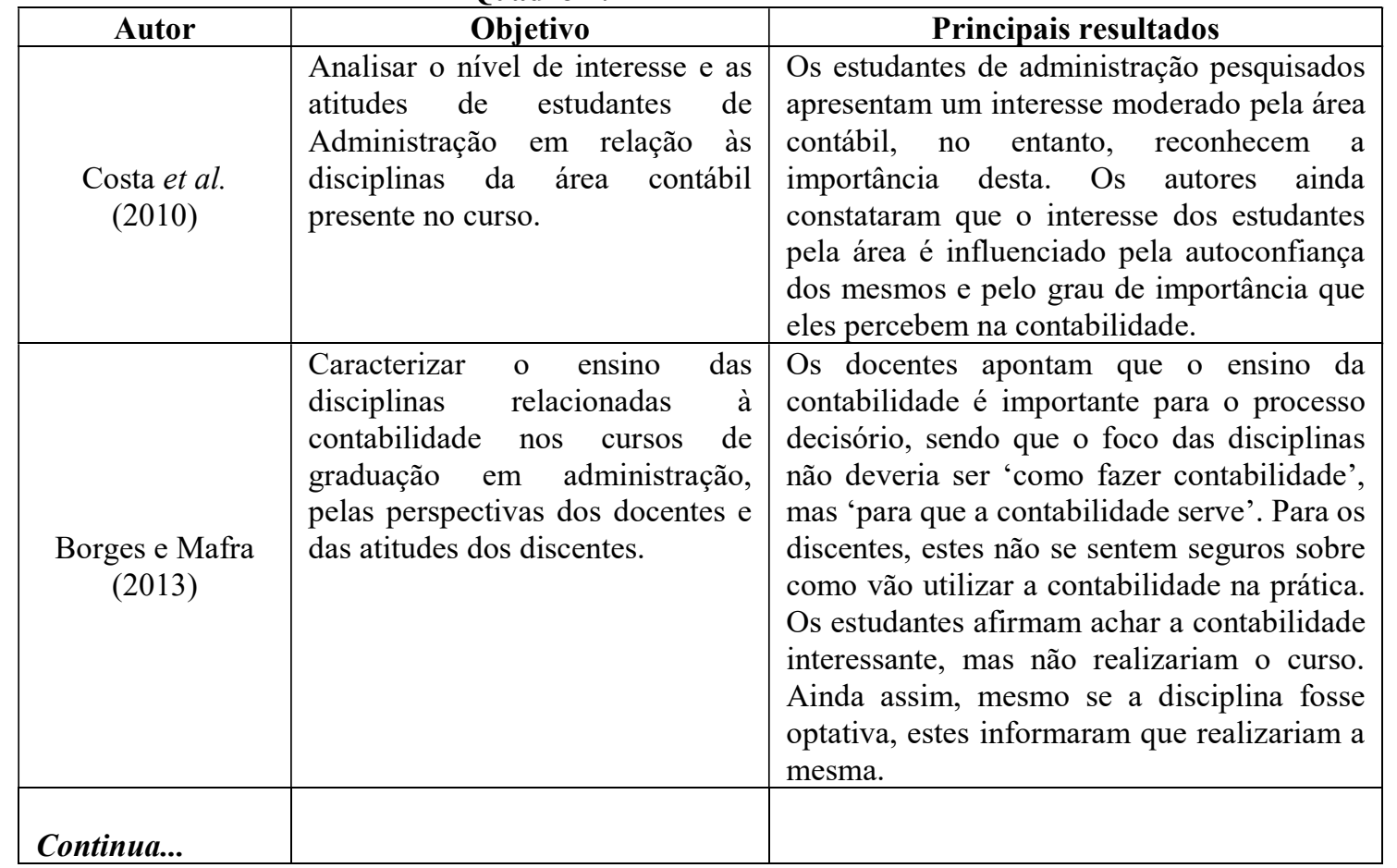




\begin{tabular}{|c|c|c|}
\hline $\begin{array}{c}\text { Panhoca et al } \\
\text { (2004) }\end{array}$ & $\begin{array}{l}\text { Investigar a interpretação } \\
\text { estudantes un } \\
\text { profissionais da área econômica e } \\
\text { financeira fazem em relação aos } \\
\text { termos básicos da área de } \\
\text { controladoria. }\end{array}$ & $\begin{array}{l}\text { Não há um consenso entre os estudantes } \\
\text { quanto ao conceito de } \\
\text { contabilidade/custos/investimento. A } \\
\text { contabilidade em certos casos é apontada } \\
\text { como registro, em outras situações como } \\
\text { informação, ou em outros momentos como } \\
\text { profissão. }\end{array}$ \\
\hline $\begin{array}{l}\text { Xavier Filho et al. } \\
\text { (2015) }\end{array}$ & $\begin{array}{l}\text { Analisar a importância conferida à } \\
\text { área de contabilidade por discentes } \\
\text { de administração e se essa } \\
\text { avaliação é sensível à experiência } \\
\text { com a disciplina de contabilidade } \\
\text { geral e de custos. }\end{array}$ & $\begin{array}{l}\text { Os alunos que não cursaram a disciplina } \\
\text { atribuíram relevância para a mesma. Aqueles } \\
\text { que já tinham cursado apresentavam o } \\
\text { mesmo nível de percepção dos que ainda não } \\
\text { haviam realizado a matéria. Dessa forma, o } \\
\text { contato com o curso não altera } \\
\text { significativamente a percepção do } \\
\text { estudantes quanto ao fato de considerar a } \\
\text { contabilidade como interessante. }\end{array}$ \\
\hline $\begin{array}{l}\text { Ismail e Kasin } \\
\text { (2011) }\end{array}$ & $\begin{array}{l}\text { Verificar os fatores que afetam o } \\
\text { desempenho dos estudantes de } \\
\text { outros cursos nas disciplinas de } \\
\text { contabilidade. }\end{array}$ & $\begin{array}{l}\text { A disciplina de contabilidade é importante } \\
\text { mesmo em outros cursos, sendo que, para que } \\
\text { o desempenho dos alunos seja favorável, não } \\
\text { se deve abordar os assuntos de forma } \\
\text { superficial. }\end{array}$ \\
\hline Floret (2017) & $\begin{array}{l}\text { Investigar a forma de } \\
\text { aprendizagem que os estudantes de } \\
\text { administração e economia utilizam } \\
\text { para adquirir conhecimento na } \\
\text { área contábil. }\end{array}$ & $\begin{array}{l}\text { Os alunos de administração preferem } \\
\text { aprender pelo conteúdo passado em classe e } \\
\text { pela realização de exercícios. Por outro lado, } \\
\text { os estudantes de economia sentem-se } \\
\text { satisfeitos em aprender por meio de leituras. }\end{array}$ \\
\hline $\begin{array}{l}\text { Muda et al. } \\
\quad(2013)\end{array}$ & $\begin{array}{l}\text { Verificar os fatores que } \\
\text { contribuem para resultados } \\
\text { insatisfatórios de estudantes que } \\
\text { não fazem o curso de ciências } \\
\text { contábeis nas disciplinas dessa } \\
\text { área. }\end{array}$ & $\begin{array}{l}\text { Os principais fatores que fazem com que os } \\
\text { alunos não apresentem resultados positivos } \\
\text { nas disciplinas de contabilidade são: a } \\
\text { matéria não é a preferida, a falta de } \\
\text { disponibilidade dos professores após as aulas, } \\
\text { questões com interpretações ambíguas nas } \\
\text { provas e acomodação dos próprios alunos. }\end{array}$ \\
\hline $\begin{array}{l}\text { Lois, Tabouratzi e } \\
\text { Makrygiannakis } \\
\text { (2017) }\end{array}$ & $\begin{array}{l}\text { Verificar a percepção dos } \\
\text { estudantes de contabilidade e de } \\
\text { outras áreas quanto aos Sistemas } \\
\text { de Informações Gerenciais. }\end{array}$ & $\begin{array}{l}\text { O uso de Sistemas de Informações Gerenciais } \\
\text { em classe reforça para os estudantes de } \\
\text { contabilidade a importância da área e para os } \\
\text { estudantes de outros cursos, traz um aumento } \\
\text { do interesse em conhecer a ciência contábil }\end{array}$ \\
\hline
\end{tabular}

Fonte: Elaborado pelas autoras (2018)

Tal como exposto no Quadro 1, tais estudos preocuparam-se tão somente em verificar a percepção dos estudantes, de uma forma geral, quanto a importância da contabilidade ou a forma de ensino-aprendizagem adotadas por docentes e discentes. Assim, diante do objetivo que foi traçado para o atual estudo, verifica-se que este traz uma ampliação do cabedal literário já existente, ampliando e enriquecendo a discussão.

\section{METODOLOGIA}

Diante dos objetivos traçados para a presente pesquisa, torna-se necessária a execução de procedimentos para que estes sejam alcançados. Nesse sentido, o atual trabalho pode ser caracterizado como descritivo, visto que pretende analisar as características de uma certa amostra, a qual é formada por estudantes de administração, tendo como forma de execução a análise quantitativa dos dados.

A pesquisa foi realizada por meio de questionário online. Tal instrumento de coleta de dados foi elaborado com base nos conceitos dos principais demonstrativos contábeis, conforme constam no Pronunciamento Contábil (26) - Estrutura das Demonstrações Contábeis. Após a 
elaboração, o formulário foi testado com estudantes do referido curso com a perspectiva de verificar a necessidade de adaptações na linguagem e formatação do questionário.

A apresentação da ferramenta de pesquisa se deu em dois blocos, sendo o primeiro com questionamentos acerca do perfil do respondente, já a segunda parte apontava diversas perguntas objetivas sobre o conceito de cada demonstrativo contábil. Todas as perguntas da segunda seção apresentavam como alternativas:

- Balanço Patrimonial;

- $\quad$ Demonstração do Resultado;

- Demonstração dos Fluxos de Caixa;

- Demonstração dos Resultados Abrangentes;

- $\quad$ Demonstração do Valor Adicionado;

- $\quad$ Demonstração das Mutações do Patrimônio Líquido;

- Demonstração dos Lucros e Prejuízos Acumulados;

- $\quad$ Notas Explicativas;

- $\quad$ Não sei.

Dessa forma, o respondente marcaria a demonstração que se enquadrasse no questionamento feito e caso este não soubesse a resposta poderia marcar a opção 'não sei'. Um resumo do questionário é apresentado no Quadro 2.

Quadro 2: Resumo do questionário

\begin{tabular}{|c|l|}
\hline Bloco do questionário & \multicolumn{1}{c|}{ Perguntas } \\
\hline Perfil do respondente & $\begin{array}{l}\text { Gênero; Período do curso; Autoavaliação sobre demonstrações contábeis; Estado } \\
\text { da Federação; Curso presencial ou EAD; Ano provável de formação; Estuda em } \\
\text { instituição pública ou privada; Turno do curso; Já estudou disciplina de } \\
\text { contabilidade geral; Já fez o curso de ciências contábeis; Quais demonstrações } \\
\text { contábeis já foram estudadas. }\end{array}$ \\
\hline $\begin{array}{c}\text { Conhecimento sobre as } \\
\text { demonstrações contábeis }\end{array}$ & $\begin{array}{l}\text { Qual a demonstração contábil que está dividida em 3 subgrupos, sendo eles: } \\
\text { Atividades operacionais, atividades de financiamento e atividades de investimento? } \\
\text { Qual a demonstração que evidencia a geração e distribuição da riqueza da } \\
\text { administração? } \\
\text { Qual o elemento que contêm informação adicional em relação à apresentada nas } \\
\text { demonstrações contábeis? } \\
\text { Qual a demonstração que compreende itens de receita e despesa que não são } \\
\text { reconhecidos na demonstração do resultado, tais como ganhos e perdas atuariais } \\
\text { em planos de pensão, ganhos e perdas derivados de conversão de demonstrações } \\
\text { contábeis de operações no exterior? } \\
\text { Qual a demonstração contábil que evidencia os ativos, passivos e o patrimônio } \\
\text { líquido da organização? } \\
\text { Qual a demonstração que evidencia as alterações em contas de capital social, } \\
\text { reservas de capital, reservas de lucro e outras contas do patrimônio líquido? } \\
\text { Qual a demonstração contábil que evidencia as receitas, despesas e a formação do } \\
\text { lucro ou prejuízo no período, de uma empresa? } \\
\text { Qual a demonstração que destaca as destinações do lucro no período e que pode ser } \\
\text { incluída na Demonstração das Mutações do Patrimônio Líquido? }\end{array}$ \\
\hline
\end{tabular}

Fonte: Elaborado pelas autoras (2018)

Os dados foram coletados via internet por meio do Google Docs entre os dias 02 de junho e 08 de julho de 2018, coletando-se 168 respostas, sendo que 144 foram consideradas válidas. Para análise foi adotada a estatística descritiva e a análise inferencial por meio do teste qui-quadrado a fim de verificar possíveis diferenças entre os grupos existentes na amostra. Os dados foram tabulados no $\mathrm{Excel}^{\mathbb{R}}$, sendo que as análises estatísticas foram realizadas no software Gretl, cujos resultados são expostos a seguir. 


\section{RESULTADOS}

\subsection{Perfil dos Respondentes}

No que se refere à amostra estudada, $53,9 \%$ dos respondentes se declararam do gênero masculino, enquanto $46,1 \%$ do gênero feminino. A maioria já estava no oitavo período de curso $(20,14 \%)$ e já haviam cursado a disciplina de contabilidade geral ou equivalente $(67,7 \%)$. Boa parte dos respondentes não haviam feito graduação em ciências contábeis e não pretendiam realizar a mesma após o término do curso de administração (64,5\%), sendo este resultado semelhante ao encontrado por Borges e Mafra (2013).

A maioria dos estudantes estudavam no regime de curso presencial $(90,97 \%)$ em instituições de ensino privadas $(56,9 \%)$ do Nordeste $(55,5 \%)$ e estavam com programação de formação em 2019 (27,78\%). Além disso, os respondentes estudavam, em sua maioria, no turno da noite $(64,7 \%)$.

Destacou-se que o balanço patrimonial já havia sido estudado pela maior parte dos estudantes participantes da pesquisa $(92,2 \%)$, seguida pela demonstração do resultado $(87,4 \%)$ e da demonstração dos fluxos de caixa $(72,5 \%)$. Tal achado confirma aquilo que foi encontrado por Fagundes et al. (2013) de que as demonstrações mais utilizadas pelos administradores no processo decisório são o balanço patrimonial, demonstração do resultado e demonstração dos fluxos de caixa. Assim, entende-se que, por serem essas as mais adotadas pelos gestores, o foco durante a graduação é justamente nesses demonstrativos. Dessa forma, é esperado que os estudantes conheçam mais essas peças, tendo em vista que estas foram estudadas pela maioria dos discentes. Sobre esse conhecimento debruça-se a próxima subseção.

\subsection{Conhecimento dos Discentes}

Em média houve um percentual de $67,01 \%$ de acertos nas questões apresentadas. Verificou-se que a maioria dos respondentes acertaram a questão que tratava do conceito do balanço patrimonial $(78,5 \%)$. Tal resultado já era esperado pois, conforme já discutido essa é a demonstração que mais é utilizada pelos administradores, o que pode ter reflexo no ensino durante a graduação. Por outro lado, a DVA foi aquela cujo os estudantes mais erraram o conceito $(66,7 \%)$. Mais uma vez a presente pesquisa se alinha ao estudo de Fagundes et al. (2013), pois no trabalho supracitado os autores afirmaram que este demonstrativo é pouco utilizado pelos gestores tendo como foco principal o usuário externo. Assim, é de compreender que este seja pouco abordado no curso de administração e que os discentes apresentem baixo conhecimento sobre ele. O resumo para este resultado é apresentado no gráfico 1 .

Gráfico 1: Nível de acertos sobre os demonstrativos contábeis

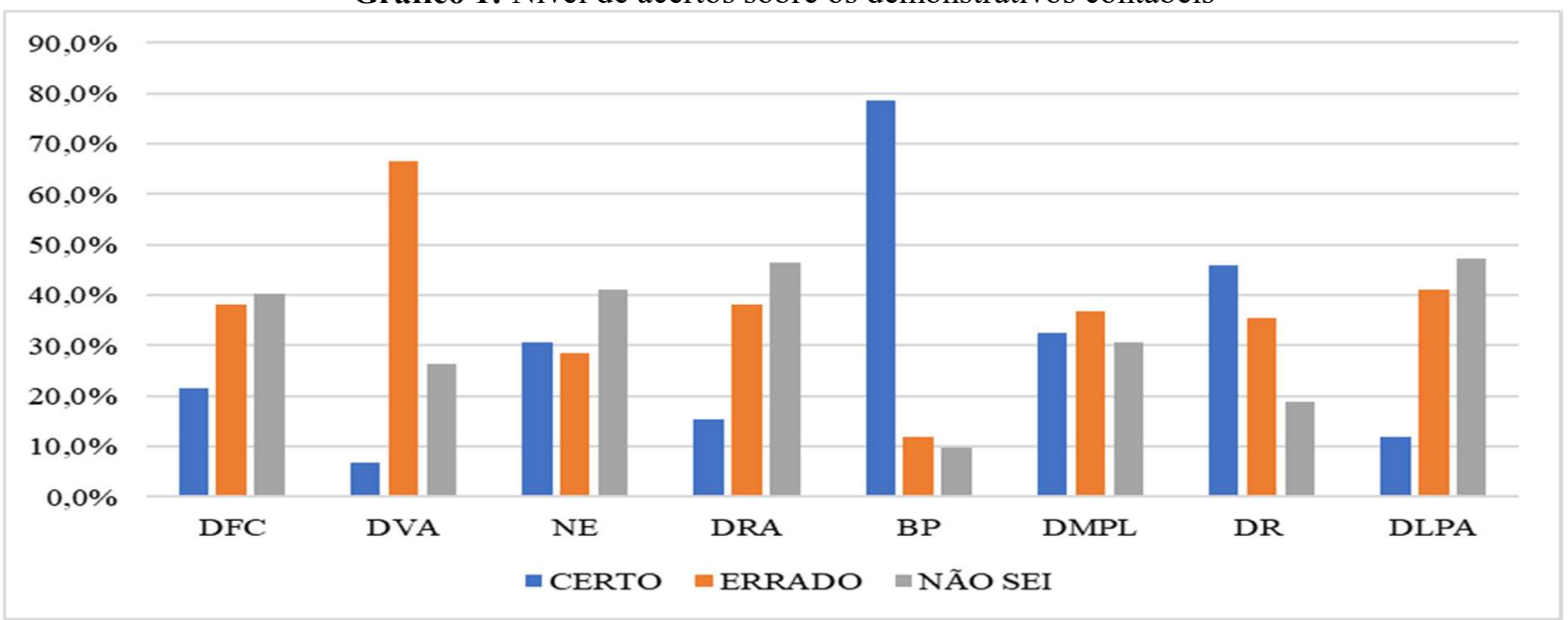

Fonte: Dados da pesquisa (2018) 
No que tange aos diversos grupos dentro da amostra, não foram encontradas diferenças entre homens e mulheres. Ou seja, o nível de conhecimento entre ambos não apresenta divergências estatisticamente significativas. Além disso o período do curso também não trouxe impacto para o fato do respondente saber mais ou menos acerca das demonstrações contábeis. Assim, entende-se que, o fato de o aluno estar terminando ou não o curso não o torna mais conhecedor acerca dos demonstrativos contábeis. Destaca-se que Xavier Filho et al. (2015) averiguaram que a percepção do estudante de administração quanto à relevância da contabilidade não muda independente deste estar no início do curso ou no final. Dessa forma, somando os resultados do presente estudo com o do trabalho supracitado, compreende-se que após cursada as disciplinas de contabilidade o estudante perde o contato com a ciência contábil e o seu interesse e conhecimento por esta permanece o mesmo, sem haver uma evolução.

Por outro lado, a nota da autoavaliação, ou seja, o conhecimento que os estudantes percebem que tem acerca dos demonstrativos contábeis foi significativo para explicar o nível de conhecimento destes acerca dos relatórios a seguir: Demonstração dos fluxos de caixa, Demonstração do Valor Adicionado, Notas Explicativas e Demonstração do Resultado Abrangente, conforme visualizado na Tabela 1. Nas demais não houve influência significativa neste aspecto.

Tabela 1: Relação entre nota da autoavaliação e conhecimento dos estudantes

\begin{tabular}{l|l|l|l|l}
\hline \multicolumn{1}{c|}{ Resultados } & $\begin{array}{c}\text { Demonstração } \\
\text { dos fluxos de } \\
\text { caixa }\end{array}$ & $\begin{array}{c}\text { Demonstração } \\
\text { do valor } \\
\text { adicionado }\end{array}$ & $\begin{array}{c}\text { Notas } \\
\text { explicativas }\end{array}$ & $\begin{array}{c}\text { Demonstração } \\
\text { do resultado } \\
\text { abrangente }\end{array}$ \\
\hline $\begin{array}{l}\text { Resultado qui- } \\
\text { quadrado }\end{array}$ & $\begin{array}{l}\mathrm{X}^{2} 18,138, \text { valor-p } \\
0,00\end{array}$ & $\begin{array}{l}\mathrm{X}^{2} 14,5148 ; \text { valor- } \\
\mathrm{p} 0,00\end{array}$ & $\begin{array}{l}\mathrm{X}^{2} 11,5639 ; \text { valor- } \\
\mathrm{p}(0,02)\end{array}$ & $\begin{array}{l}\mathrm{X}^{2} 15,7042 ; \text { valor- } \\
\mathrm{p} 0,00)\end{array}$ \\
\hline $\begin{array}{l}\text { Autoavaliação } \\
\text { menor que } \\
\text { (acertos) }\end{array}$ & $10,0 \%$ de acertos & $2,5 \%$ de acertos & $17,5 \%$ de acertos & $2,5 \%$ de acertos \\
\hline $\begin{array}{l}\text { Autoavaliação } \\
\text { igual a 3 (acertos) }\end{array}$ & $16,9 \%$ de acertos & $3,07 \%$ de acertos & $32,3 \%$ de acertos & $13,8 \%$ de acertos \\
\hline $\begin{array}{l}\text { Autoavaliação } \\
\text { maior que } \\
\text { (acertos) }\end{array}$ & $41,0 \%$ de acertos & $17,9 \%$ de acertos & $41,0 \%$ de acertos & $30,1 \%$ de acertos \\
\hline
\end{tabular}

Fonte: Dados da pesquisa (2018)

Com isso, entende-se que quanto maior é a percepção do aluno sobre seu próprio conhecimento acerca dos demonstrativos contábeis, maior é a sua propensão a acertar tais conceitos. Costa et al. (2010) destacou que o interesse do aluno de administração quanto à contabilidade está ligado à sua autoconfiança acerca do conteúdo aprendido. Assim, é possível concluir, tendo em vista os resultados aqui demonstrados, que o aluno autoconfiante quanto ao seu conhecimento tende a ter um desempenho melhor.

Constatou-se que o fato do estudante fazer um curso na modalidade presencial ou a distância não interferiu no seu nível de conhecimento. Diante disso, destaca-se o comentário de Nascimento Czykiel e Figueiró (2013) de que apesar de ainda existir um certo preconceito com cursos $\mathrm{EaD}$, o sucesso do ensino-aprendizagem depende muito da exploração do conteúdo, dos recursos e das ferramentas disponíveis. Destaca-se ainda que Machado et al. (2015) consideram que a modalidade a distância requer uma maior dedicação do estudante, o que pode trazer bons resultados. Dessa forma, entende-se que não é a modalidade de aulas e sim a dedicação do aluno que o faz adquirir um maior conhecimento.

Ressalta-se também que o discente estudar em uma instituição pública ou privada não foi significativo, estatisticamente, para influenciar seu conhecimento acerca das demonstrações contábeis. No entanto, Nicolini et al. (2014) destacou que as entidades de ensino públicas apresentam melhores resultados em avaliações como ENADE, por exemplo. Porém, ressalta- 
se que o resultado do presente estudo vai de encontro ao que foi destacado pelo autor supracitado, pois está restrito a um tema específico e delimitado.

Já o turno que o estudante assiste as aulas do curso foi estatisticamente significativo para explicar o nível de conhecimento dos alunos acerca dos demonstrativos contábeis a seguir: Demonstração dos fluxos de caixa, Demonstração do Valor Adicionado, Notas Explicativas e Demonstração do Resultado Abrangente, conforme visualizado na Tabela 2. Nas demais não houve influência significativa neste aspecto.

Tabela 2: Relação entre nota da autoavaliação e conhecimento dos estudantes

\begin{tabular}{l|c|c}
\hline \multicolumn{1}{c|}{ Resultados } & Notas explicativas & $\begin{array}{c}\text { Demonstração das mutações do } \\
\text { patrimônio líquido }\end{array}$ \\
\hline Resultado qui-quadrado & $\mathrm{X}^{2} 9,80065$, valor-p 0,02 & $\mathrm{X}^{2} 9,24763$, valor-p 0,02 \\
\hline Matutino & $47,10 \%$ de acertos & $79,4 \%$ de acertos \\
\hline Vespertino & $25,0 \%$ de acertos & $25,0 \%$ de acertos \\
\hline Noturno & $34,1 \%$ de acertos & $35,2 \%$ de acertos \\
\hline Ead & $45,45 \%$ de acertos & $63,6 \%$ de acertos \\
\hline
\end{tabular}

Fonte: Dados da pesquisa (2018)

Foi possível verificar que, de uma forma geral, os alunos do curso matutino apresentaram melhor desempenho no conhecimento sobre esses demonstrativos, seguido do desempenho dos alunos dos cursos Ead. No que se refere ao turno, consolida-se o resultado do presente trabalho com o que foi apontado por Pavão e Castro (2017) de que os alunos de cursos diurnos tendem a apresentar melhores desempenhos do que os estudantes de cursos noturnos, pois aqueles apresentam mais tempo para atividades extraclasse, menor número de faltas, acentuando-se a isso, o fato de que alunos de cursos noturnos agregam outras atividades, tais como o trabalho.

Já no que tange ao curso a distância, retorna-se mais uma vez ao comentário de Machado et al. (2015) de que nesta modalidade é requerido um maior compromisso do aluno. Assim, é possível que este termine criando uma maior independência acadêmica, aprendendo mais e apresentando melhores resultados em determinados aspectos.

Por fim, verificou-se que o fato do aluno já ter realizado ou não a disciplina de contabilidade, afetou no nível de conhecimento destes acerca de demonstrativos como: balanço patrimonial, demonstração do resultado, demonstração das mutações do patrimônio líquido e demonstração dos lucros e prejuízos acumulados, tal como pode ser verificado na Tabela 3.

Tabela 3: Relação entre nota da autoavaliação e conhecimento dos estudantes

\begin{tabular}{|c|c|c|c|c|}
\hline Resultados & $\begin{array}{c}\text { Balanço } \\
\text { Patrimonial }\end{array}$ & $\begin{array}{c}\text { Demonstração } \\
\text { das Mutações do } \\
\text { Patrimônio } \\
\text { Líquido }\end{array}$ & $\begin{array}{l}\text { Demonstração } \\
\text { do Resultado }\end{array}$ & $\begin{array}{c}\text { Demonstração } \\
\text { dos lucros e } \\
\text { prejuízos } \\
\text { acumulados }\end{array}$ \\
\hline $\begin{array}{l}\text { Resultado } \\
\text { quadrado }\end{array}$ & $\begin{array}{l}X^{2} 20,778, \text { valor-p } \\
0,00\end{array}$ & $\begin{array}{l}X^{2} 11,5046, \text { valor- } \\
\text { p } 0,01\end{array}$ & $\begin{array}{l}X^{2} 7,90693, \text { valor- } \\
\text { p } 0,05\end{array}$ & $\begin{array}{l}X^{2} \quad 9,52141 ; \\
\text { valor-p } 0,02\end{array}$ \\
\hline Sim, e já fui aprovado & $95,9 \%$ de acertos & $74,7 \%$ de acertos & $86,9 \%$ de acertos & $\begin{array}{ll}59,60 \% & \mathrm{de} \\
\text { acertos } & \\
\end{array}$ \\
\hline $\begin{array}{l}\text { Estou realizando a } \\
\text { disciplina }\end{array}$ & $93,7 \%$ de acertos & $81,25 \%$ de acertos & $75,0 \%$ de acertos & $\begin{array}{l}31,25 \% \\
\text { acertos }\end{array}$ \\
\hline $\begin{array}{l}\text { Ainda não realizei a } \\
\text { disciplina }\end{array}$ & $78,3 \%$ de acertos & $\begin{array}{l}52,17 \% \text { de acertos } \\
\text { de acertos }\end{array}$ & $73,9 \%$ de acertos & $\begin{array}{l}52,17 \% \\
\text { acertos }\end{array}$ \\
\hline $\begin{array}{l}\text { Fui reprovado e estou } \\
\text { realizando novamente }\end{array}$ & $50,0 \%$ de acertos & $25,0 \%$ & $50,0 \%$ de acertos & $\begin{array}{l}0,0 \% \\
\text { acertos }\end{array}$ \\
\hline
\end{tabular}

Fonte: Dados da pesquisa (2018)

Assim, verificou-se que, os alunos que já haviam cursado a disciplina e tinham sido aprovados, bem como aqueles que estavam estudando a matéria de contabilidade no momento 
da pesquisa apresentaram melhor desempenho no conhecimento acerca dos demonstrativos supracitados, na maioria dos casos, que os demais estudantes.

Por outro lado, nas demais demonstrações contábeis não foram encontradas diferenças significativas, o que denota que o fato de o estudante já ter frequentado as aulas de contabilidade não o faz ter um conhecimento maior sobre tais peças do que aqueles que ainda não realizaram a disciplina.

Com isto, encerra-se a seção dos resultados da pesquisa, encaminhando-se agora para o fechamento deste trabalho, no qual são apresentadas as conclusões desta pesquisa, suas limitações e sugestões para futuras investigações.

\section{CONSIDERAÇÕES FINAIS}

Esta pesquisa teve como objetivo identificar o nível de conhecimento dos estudantes de administração quanto à finalidade das Demonstrações Contábeis obrigatórias no Brasil, verificando se há associação entre o perfil desse respondente e seu nível de conhecimento, cujo perfil contemplou o turno em que estuda, tipo de instituição, e, ter cursado ou não disciplinas de contabilidade geral ou correlata. Para tanto, foi realizada uma pesquisa descritiva e quantitativa, com alunos da graduação em administração, por meio de um questionário online, contemplando perguntas referentes aos seguintes relatórios contábeis: Balanço Patrimonial; Demonstração do Resultado do Exercício; Demonstração do Resultado Abrangente; Demonstração do Fluxo de Caixa; Demonstração do Valor Adicionado; Demonstração das Mutações do Patrimônio Líquido, Demonstração dos Lucros e Prejuízos Acumulados e Notas Explicativas.

Por meio da ferramenta utilizada, obteve-se uma amostra de 144 respondentes, dos quais a maioria declarou pertencer ao gênero masculino, além de estarem no $8^{\circ}$ período do curso e já ter cursado a disciplina contabilidade geral ou equivalente. Quase todos os respondentes faziam curso presencial, no turno da noite e em instituições privadas na região Nordeste.

Em relação às demonstrações contábeis que mais estudaram, informaram ter sido o Balanço Patrimonial, Demonstração do Resultado do Exercício e Demonstração dos Fluxos de Caixa. Sobre o conhecimento a respeito do conjunto desses documentos, o maior número de acertos correspondeu ao conteúdo do Balanço Patrimonial e o de menor acerto, a Demonstração do Valor Adicionado. A autoavaliação quanto a esse conhecimento coincidiu com maioria das respostas obtidas nas questões sobre DFC, DVA, DRA e Notas Explicativas. Além disso, o nível de conhecimento quanto a esses demonstrativos mostrou-se associado ao turno em que o aluno estuda, sendo o melhor desempenho apresentado por aqueles que cursam pela manhã, em seguida dos $\mathrm{EaD}$. Por fim, ter cursado ou não a disciplina de contabilidade geral ou correlata, afetou o nível de conhecimento sobre o Balanço Patrimonial, DMPL, DRE e DLPA.

Por meio desses achados foi possível constatar as demonstrações que os alunos apresentaram mais ou menos dificuldades em termos de conhecimento, e, encontrar os elementos que se mantiveram associados a esse nível de conhecimento. Tal informação pode contribuir para nortear professores de contabilidade que ministram esse tipo de conteúdo no curso de administração. Sendo assim, ações podem ser criadas em prol de melhor explanar o assunto nas aulas para o referido curso, uma vez que administradores necessitam saber a finalidade de cada demonstração, e não as elaborar, pois esse é papel do contador.

Esses resultados foram limitados a apenas a amostra que se conseguiu obter com a disponibilização do questionário online em certo período, portanto, não é possível generalizar, cabendo em pesquisas futuras, realizar, dentro de cada instituição uma pesquisa na qual fosse possível criar simulações em que os futuros administradores tivessem que tomar decisões com base em informações das demonstrações contábeis, e assim, avaliar quais instrumentos esses alunos adotariam. 


\section{REFERÊNCIAS}

ALMEIDA; J.E.F. Fundamentos de Contabilidade para os Negócios: Introdução à Contabilidade. São Paulo: Elsevier Brasil, 2016.

ALVES, Márcio. Programa de Aprendizagem. Disponível em: <http://preview.univille.net>. Acesso em 11 de julho de 2018.

BOLDT; M.N. Assessing Students'Accounting Knowledge: A Structural Approach. Journal of Education for Business, v.76, n.5, p.262-269, may-jun, 2001.

BORGES; G.F.; NAVES; F. Ensino de contabilidade na graduação em administração: uma análise sob a perspectiva discente. Revista de Contabilidade e Organizações, v.21, p. 59-70, 2014.

BORGES; G.F.; NAVES; F. Ensino de contabilidade na graduação em administração: uma análise sob a perspectiva discente. Revista de Contabilidade e Organizações, v.21, p. 59-70, 2014.

BRASIL. Lei 6.404 de 15 de dezembro de 1976 - Dispõe sobre a Sociedade por Ações. Disponível em: < http://www.planalto.gov.br/ccivil_03/leis/L6404consol.htm> Acesso em março de 2018.

BRASIL. Lei $n^{\circ}$ 6.404, de 15 de dezembro de 1976. Dispõe sobre as Sociedades por Ações. Disponível em: $<$ http://www.planalto.gov.br/ccivil 03/Leis/L6404consol.htm $>$. Acesso em 09 de julho de 2018.

BRASIL. Norma Brasileira de Contabilidade, NBC TG 26 (R5) - Apresentação das Demonstrações Contábeis. Disponível em: $<$ http://www1.cfc.org.br/sisweb/SRE/docs/NBCTG26(R5).pdf $>$. Acesso em 09 de julho de 2018.

BRASIL. Norma Brasileira de Contabilidade, NBC TSP Estrutura Conceitual, de 23 de setembro de 2016. Aprova a NBC TSP ESTRUTURA CONCEITUAL - Estrutura Conceitual para Elaboração e Divulgação de Informação Contábil de Propósito Geral pelas Entidades do Setor Público. Disponível em: $<$ http://static.cpc.aatb.com.br/Documentos/147_CPC00_R1.pdf $>$. Acesso em 09 de julho de 2018.

CONCEIÇÃO; M.G.; OLIVEIRA; N.C.; GOMES; S.M.S.; OLIVEIRA; N.S; FREIRES; F.G.M. Comparação do Nível de Conhecimento sobre Contabilidade Social e Ambiental dos Estudantes Ingressos e Formandos do Curso de Ciências Contábeis da Universidade Federal Da Bahia. Revista de Gestão e Contabilidade da UFPI, v.1, n.2, p.3-22, julho-dezembro de 2014.

COORDENAÇÃO DE APERFEIÇOAMENTO DE PESSOAL DE NÍVEL SUPERIOR. Editor agrupa milhões de documentos de patentes nacionais e internacionais. Publicado em 27 de abril de 2017. Disponível em: < $\mathrm{http}: / / \mathrm{www} . c a p e s . g o v . b r / c o m p o n e n t / c o n t e n t / a r t i c l e / 36-s a l a i m p r e n s a / n o t i c i a s / 8371-e d i t o r-$ agrupa-milhoes-de-documentos-de-patentes-nacionais-e-internacionais $>$ Acesso em março de 2018.

COSTA; M.S; LIBONATI; J.J.; RODRIGUES; R.N. Conhecimentos Sobre Particularidades da Contabilidade Rural: Um Estudo Exploratório com Contadores da Região Metropolitana de Recife. Contexto, v.4, n.7, p.1-24, 2004.

DIAS FILHO; J.M. A linguagem utilizada na evidenciação contábil: uma análise de sua compreensibilidade à luz da teoria da comunicação. Caderno de Estudos, v.13, n.24, p. 38-49, julho/dezembro, 2000. 
FAGUNDES; J.A.; SANTANA; A.F.B.; BACH; E.G.; MAROSTICA; J. Aplicabilidade da Contabilidade Gerencial como Ferramenta de Gestão para Tomada de Decisões nas Indústrias de Pinhalzinho/SC. Revista de Contabilidade Dom Alberto, v.1, n.3, p. 1-22, junho, 2013.

FEIL; A.A.; HABERKAMP; A.M.; AZEREDO; A.J.; ORSO; T.M.; KRONBAUER; C. Análise do Nível de Conhecimento do Profissional Contábil acerca da Contabilidade Ambiental e suas Variáveis Intervenientes. Revista Ambiente Contábil,v.9, n.1, p. 223-245, jan/jun de 2017.

GITMAN, L. J. Princípios de Administração Financeira. São Paulo: Pearson Prentice Hall, 2010.

GOMES; S..S.; SOUZA; L.E.; CRUZ; T.S.; GOMES; I.B. Nível de Conhecimento dos Futuros Profissionais de Contabilidade do Estado da Bahia: Uma Análise à Luz dos Conceitos Básicos Presentes nas Normas Brasileiras de Contabilidade. Revista de Administração, Contabilidade e Sustentabilidade, Vol. 5, n. 2, p.104-121, 2015.

IUDÍCIBUS, S. de. Análise de Balanços. 7 Edição. SP: Editora Atlas, 1998.

IUDÍCIBUS, S. et al. Manual de Contabilidade Societária.11ª ed. São Paulo: Atlas, 2010.

IUDÍCIBUS; S.; MARTINS; E.; CARVALHO; E. Contabilidade: aspectos relevantes da epopéia de sua evolução. Revista Contabilidade \& Finanças, v. 16, n.38, Maio/agosto de 2015

LOUW; J.; NIDA; E. Léxico Grego-Português do Novo Testamento. São Paulo: Sociedade Bíblica do Brasil, 2013.

LUCAS; U.; MLADENOVIC; R. The identification of variation in students' understandings of disciplinary concepts: the application of the SOLO taxonomy within introductory accounting. Higher Education, v.58, issue 2, p.257-283, august, 2009,

MACHADO; D.G.; CZARNESK; F.R.; DOMINGUES; M.J.C.S. Perfil das Metodologias de Ensino Presencial e a Distância na Graduação em Administração. Estudo \& Debate, v. 22, n. 2, p. 105-122, 2015.

MARION, J. C. Análise das demonstrações contábeis. $7^{\text {a }}$ ed. Atlas: São Paulo, 2012.

NASCIMENTO; L.F.; CZYKIEL; R.; FIGUEIRÓ; P.S. Presencial ou a Distância: a Modalidade de Ensino Influencia na Aprendizagem? Administração: Ensino e Pesquisa, v.14, n.2, p. $311-341$, abril-junho, 2013.

NICOLINI; R.O.B.; TORRES; A.A.G.; CALDERÓN; P.A.L. Desempenho dos Cursos de Bacharelado em Administração no Brasil: Uma Análise dos Resultados no Exame Nacional de Desempenho (Enade) em 2006, 2009 e 2012. In: XIV Colóquio Internacional de Gestão Universitária, Florianopólis, Santa Catarina, Brasil, 3,4 e 5 de dezembro de 2014. Disponível em: https://repositorio.ufsc.br/bitstream/handle/123456789/131785/2014-161.pdf?sequence=1

NUNES; I.V.; COSTA; P.S.; MARQUES; A.V. Nível de Conhecimento dos Discentes em Ciências Contábeis sobre o Pronunciamento Conceitual Básico. Revista Universo Contábil, v. 12, n. 1, p. 87-104, jan./mar., 2016.

PAVÃO; A.C.; CASTRO; C.R. O desempenho acadêmico dos estudantes cotistas e não cotistas no contexto inclusivo da Lei 12.711: uma análise comparativa na Universidade Federal Rural do Semi-Árido. Revista Brasileira de Ensino Superior, v.3, n.3, p.54 - 79, 2017.

RIBEIRO; O.M. Contabilidade Geral Fácil. 9 ed. São Paulo: Saraiva, 2013.

SANTOS; A importância da contabilidade na administração da micro e pequena empresa. (C) Revista Conteúdo, Capivari, v.2, n.1, p. 38-43, jan./jul. 2012. 
SIHOMBING; R.P. The Indonesia Best Sustainability Report as a Student's Accounting Tool to Understand CRS Concept. Jurnal Dinamika Akuntansi, v.7, n.2, p.161-166, Seotenber, 2015.

SILVA; H.H.A; ALBUQUERQUE; L.S.; LUZ; J.R.M.; DANTAS; R.F. Imparment test: um estudo sobre o nível de conhecimento dos alunos de ciências contábeis das Universidades Públicas do Estado da Paraíba. Revista Reuna, v.21, n.1, p.29-52, p.29-52, jan - mar, 2016

STRONG; J.; PORTS; K. IT Knowledge: What Do Accounting Students Think They Know? Do You Know More Than I Do? An Exploratory Study. Review of Business Information Systems, v.19, n.2, p.39-50, December, 2015.

\section{SOBRE AS AUTORAS}

NADIELLI MARIA DOS SANTOS GALVÃO é mestra em Ciências Contábeis/UFPE e graduada em Ciências Contábeis/UFPE. Professora Assistente na Universidade Federal de Sergipe.

E-mail: profa.nadielligalvao@gmail.com

ANDREZA CRISTIANE SILVA DE LIMA é mestra em Ciências Contábeis/UFPE e graduada em Ciências Contábeis/UFPE. Professora na Faculdade José Lacerda Filho de Ciências Aplicadas e na Faculdade de Ciências Humanas de Pernambuco.

E-mail: andrezacslima@gmail.com

LUANA LEITE PEREIRA DOS SANTOS é graduada em Ciências Contábeis/UFPE. Coordenadora administrativa-financeira SENAI/PE.

E-mail: luana_llpds@hotmail.com 